Resumo

As acusacões de Masson contra Freud, por ter abandonado a teoria da sedução, inanguraram uma polêmica em torno da validade dessa teoria na explicação da histeria e em torno da própria psicanálise. Seguidores propõem a volta dessa teoria, denunciando o abuso infantil, e acusam Freud de covarde e ambicioso. Já os opositores vêem nesse suposto abandono não o descaso com a infância, mas a possibilidade do desenvolvimento da psicanálise. Analisamos esses discursos e conchimos que Frend, a partir da teoria da sedução, deixou sua herança: a teorização, para a psicanálise em torno da fantasia e da sexualidade infantil e, entre outras contribuiçoes, elementos dispersos com os quais Laplanche pôde construir a teoria da sedução generalizada.

Descritores: abuso sexual; trauma; infância; histeria; sexualidade infantil; psicanálise

\section{HISTERIA, TRAUMA E SEDUÇÃO: "O QUE LHE FIZERAM POBRE CRIANÇA" (UM FREUD COVARDE?)}

\author{
Viviana $C_{\text {arola }}$ elasco Martinez \\ Gustavo Adolfo Ramos Mello Neto \\ Manuela Caroline Ferreira Lima
}

\section{【ntrodução}

O trauma de sedução ocupa um lugar originário no discurso sobre a histeria. Freud, como se sabe, atribuiu-lhe importante valor etiológico em relação à histeria e à neurose obsessiva. Sabemos também que a carta 69 a Fliess, do outono de 1897, que inaugura os novos rumos tomados pelo pensamento freudiano, principalmente sobre o papel da fantasia e da sexualidade infantil, abre caminho para a des-

Docente da Universidade Estadual de Maringá, coordenadora do Laboratório de Estudos e Pesquisa em Psicanálise e Civilização.

- Pós-doutorado em psicanálise na Universidade de Paris VII, docente do da Universidade Estadual de Maringá.

- - Psicóloga, especializanda do curso "Psicoterapias na Infância", do Departamento de Psicologia Médica e Psiquiatria da UNICAMP. 
crença em torno do trauma de sedução ou, mesmo, para uma reinterpretação. O que temos, então, é, talvez, um período de silêncio até os anos 50, quando o filho de Fliess, Robert, volta a falar sobre a importância do trauma de sedução, mas sem grandes efeitos (citado por Masson, 1984); e nos anos 80, a partir da publicação de Atentado à verdade: a supressão da teoria da sedução por Freud, de J. Masson (1984), quando se inaugura certa polêmica em torno do "abandono" da teoria da sedução por Freud

É dessa polêmica que o presente artigo trata, principalmente a partir do confronto de diversas posições, o que não somente dá atualidade à teoria da sedução, como também abre uma via de reflexão sobre os próprios rumos da psicanálise.

Assim, iremos apresentar um pouco do percurso da teoria do trauma de sedução em Freud, o suposto abandono dessa teoria, as causas, "a verdade", os que defendem Freud, seus opositores e, finalmente, o possível legado de Freud.

Este trabalho é parte de pesquisa mais ampla sobre $A$ histeria ${ }^{1}$ e teve como fonte artigos indexados nos bancos de dados da Associação Americana de Psicologia (A.P.A.) - PsycInfo.

\section{Infância, trauma e sedução}

Wasserman e Rosenfeld (1992) traçam um interessante panorama histórico do abuso sexual infantil em várias épocas; desde relatos da Antigüidade, passando pelas teorias de Freud e as contribuições da psicanálise em relação à infância, até as propostas da neuropsiquiatria a esse respeito. Nesse panorama, os autores enfocam a diversidade de atitudes em torno do comportamento sexual relacionado às crianças, que oscila entre um total desamparo destas últimas - submetidas a abusos e culpabilizadas por eles - e atitudes de preservação dos inocentes, principalmente em relação ao que se entendeu como pecado. Nessas atitudes, uma forte ambigüidade se revela: na Idade Média, por exemplo, haveria um excesso de regras para inibir a relação sexual entre mãe e filho, mas, ao mesmo tempo, certa permissividade em torno da relação sexual pai-filha.

Os autores trazem também as idéias de Kraft-Ebing (citado por Wasserman \& Rosenfeld, 1992) do início do século XX, sobre a Anaesthesia Sexualis, ou a condição de inocência sexual infantil, para quem apenas em crianças doentes despertava-se a sexualidade; um despertar provocado pelo contato sexual com adultos. Ao passarem por Freud, Wasserman e Rosenfeld (1992)referem-se ao tratamento da histeria e às idéias em torno da vitimização da criança que influenciaram o desenvolvimento da teoria da sedução e, 
mais tarde, desembocaram nas descobertas sobre a sexualidade infantil. O mérito de Freud estaria precisamente nas mudanças favoráveis provocadas em torno do pensamento sobre a infância e a família. Freud teria apontado à sociedade científica que uma patologia como a histeria não possui causas exclusivamente biológicas, mas também diversas influências ambientais que não se restringem apenas à sedução propriamente dita.

Masson (1984) também nos leva à obra de Freud, e retoma as idéias trabalhadas em "A Etiologia da Histeria" (1896, citado por Masson, 1984); obra na qual, sabemos bem, o autor declara que a histeria é ocasionada por um trauma sexual na infância, decorrente da sedução por parte de um adulto e com graves conseqüências para a vítima. Ao longo do seu livro, Masson (1984) defende a validade da teoria da sedução e critica Freud por tê-la abandonado.

Por sua vez, Houpainen (2002), baseado nos argumentos de Masson, defende uma nova conceituação de trauma. Inspirada nas denúncias das feministas do abuso sexual de crianças, essa teoria propõe um retorno à tradição de Charcot, Janet e dos primeiros tempos do trabalho de Freud com Breuer, em que as concepções em torno da dissociação pelo trauma propunham-se como a melhor explicação (Van der Kolk et al., 1996, citado por Huopainen, 2002) $)^{2}$.

Bayer e Connors (1988) consideram também a importância de reconhecer a sedução como fonte geradora de traumas, e isso tendo em vista a proteção das vítimas. Para eles, a mudança que Freud imprimira em sua teoria, ao introduzir o complexo de Édipo e a fantasia em torno do desejo infantil, teria transformado a criança, na experiência real do abuso, em cúmplice voluntária. Nas sociedades em que existe a socialização por gênero, haveria todo um processo de culpabilização da vítima e a isenção de culpa dos autores de ataques sexuais ${ }^{3}$, o que favoreceria as relações assimétricas de poder e o abuso.

Gammelgaard (1992) tem outro ponto de vista. A autora afirma que a descoberta do fenômeno da fantasia permite pensar numa nova conceituação para a idéia de trauma e para a histeria, principalmente porque enfatiza os aspectos endógenos do indivíduo e não apenas os fatores externos, como as experiências de sedução retratadas nos primórdios da psicanálise. A autora considera que o trauma seria uma proteção egóica que se originaria quando falhasse a barreira contra o estímulo indesejado. Gammelgaard (1992) retoma, então, as idéias de Freud expostas nos "Estudos sobre a histeria" e destaca, ainda, o conceito de Nachträglichkeit (com posterioridade), lembrando de "O Homem dos Lobos", para consi-

124 Estilos da Clínica, 2007, Vol. XII, n²2, 122-141 
derar o aparecimento de uma memória traumática. Trata-se, nesse caso, da aquisição de significado de um evento original, ocorrido na infância e no âmbito da experiência pré-sexual, decifrado, mais tarde, por outro evento, durante a puberdade, em que se associa a cena inicial a conteúdos sexuais, isto é, edípicos. Dessa maneira, a significação atribuída liberta a repressão e constitui o trauma.

O que a autora traz de novo, com relação a outros discursos é a idéia de que a fantasia também provoca uma situação de perigo que não se configurará em abuso físico em si, mas no desamparo, que terá na angústia o sinal inequívoco da ameaça. Esse acontecimento relacionaria a memória traumática a um trabalho fantasmático de ocultação de uma sexualidade auto-erótica, que se esconderia atrás da fantasia de sedução e passividade.

Anuncia-se, então, nesses discursos sobre sedução, trauma e infância, a polêmica em torno do abandono da teoria da sedução. O livro de Masson (1984) com a defesa da teoria da sedução será um divisor de águas.

\section{Masson, Freud: os múltiplos lugares da verdade}

Como foi apontado, em 1984, Masson, então diretor de Projetos do Sigmund Freud Archives, publica Atentado à verdade: a supressão da teoria da sedução por Freud. Nesse livro, o autor afirma que a teoria inicial da sedução elaborada (e posteriormente abando- nada) por Freud ainda teria validade clínica e científica. O autor relata que, nos anos 50, Robert Fliess, filho de W. Fliess, o amigo de Freud, trouxe de volta essa discussão. R. Fliess considera que Freud teria errado ao abandonar essa teoria e defende a sua reincorporação na teoria psicanalítica com suas implicações para a clínica. $\mathrm{O}$ argumento mais forte apresentado por R. Fliess é bombástico; seria o fato de ele mesmo ter sido vítima de abuso sexual por parte do pai, o talvez mais famoso interlocutor de Freud, justamente durante a descoberta da sedução como causa da histeria, mas também da descrença na neurótica.

Masson (1984) relata, ainda, que Ferenczi continuou defendendo a teoria da sedução mesmo com a oposição de Freud. Por ocasião do XII Congresso Internacional, em 1932, Freud teria sugerido a Ferenczi que não apresentasse essas idéias - precisamente para preservar a sua reputação, supõe Masson - e teria qualificado de regressivo o comportamento intelectual e afetivo do seu discípulo.

É dessa maneira que, para Masson (1984), a ambos os autores, R. Fliess e Ferenczi, teria sido negada a credibilidade. O "abandono" da teoria da sedução atenderia, pois, à ambição de Freud de tornar a psicanálise uma ciência aceita e universal, o que a teoria da sedução não permitiria. É, então, a partir desses argumentos de Masson (1984), que vamos encontrar os adjetivos "covarde" e "ambicioso" atribuídos a Freud.

Chama a atenção que essa polêmica em torno do abandono, ou su- 
posto abandono da teoria da sedução, parece se efetivar a partir do livro de Masson (1984) ${ }^{4}$. Talvez por se duvidar da veracidade dos argumentos do filho de Fliess, tomandoos como mera fantasia? Talvez porque Ferenczi estava perturbado emocionalmente? Talvez porque o livro de Masson traz o sugestivo título "Atentado à verdade...”? Talvez porque a isso se alia o apelo visual do livro - na edição brasileira, o título se apresenta em grandes letras prateadas? Ou porque ele traz, na quarta capa, a informação de que por causa desse livro o autor perdeu o cargo de Diretor de Projetos dos Arquivos Freud? Por outro lado, a resposta pode ser encontrada no fato de Masson apresentar provas documentais de seus argumentos. Mas qual seria a verdade?

Vejamos, pois, as "provas" que nos aporta Masson (1984). O pai da psicanálise, diz o autor, não poderia ignorar a importância do abuso sexual, uma vez que havia estudado em Paris, com Charcot. Durante esses meses, teve acesso não apenas à produção literária da época, que denunciava o abuso sexual (Brouardel, Bernard e Tardieu, o próprio Charcot e Gley, entre outros ${ }^{5}$ ), mas ele mesmo teria visitado várias vezes o necrotério de Paris. O próprio Freud, continua Masson (1984), faz referência às aulas de Brouardel nesse local em que se examinavam os efeitos da violência praticada pelos adultos em pequenas crianças.

Para Masson (1984), isso tudo provaria que Freud fora testemunha, em Paris, de uma realidade grave que se denunciava e que teria fornecido 
motivos para sustentar sua teoria em torno do trauma de sedução e da histeria. Por outro lado, o autor insiste, outros trabalhos franceses publicados na mesma época vão apresentar outros argumentos que reduzirão a criança à categoria de mentirosa e fantasiosa, de forma a negar o abuso - literatura a que, segundo Masson, Freud também teve acesso.

O discurso de Fournier, por exemplo, de 1880 (citado por Masson, 1984), teria tido o objetivo de defender a suposta honra de homens injustamente acusados. Curiosamente, outro artigo de Brouardel (1883, citado por Masson, 1984) sustenta a tendência da criança a inventar histórias graças a sua imaginação e a mentir em razão de uma degeneração mental ${ }^{6}$. Isso se aliaria à ignorância dos pais, que chegam a confundir uma simples inflamação da vulva com atentados sexuais à filha.

Esses argumentos, continua Masson (1984), teriam justificado o abandono da teoria da sedução por Freud. Mas, note-se que, no caso de Brouardel, Masson nos apresenta duas posturas, ao menos aparentemente, bem contraditórias. Cita Brouardel, que argumentaria a favor da existência de abusos reais, e cita o mesmo autor que sustentaria a tendência à invenção por parte dos pais da suposta vítima ou à sugestionabilidade por parte criança, caracterizando assim a falta de veracidade do abuso sexual e a força da fantasia. Afinal, qual seria a postura de Brouardel? Teria ele mudado algumas vezes de opinião? Além disso, é difícil aceitar a "sugestionabilidade" do próprio pai da psicanálise, e supor que se deixaria influenciar ora por um discurso que denuncia o abuso sexual, ora por um discurso que nega essa realidade. Entre esses dois momentos, temos o incessante trabalho de Freud traçando o percurso criativo da psicanálise.

Surpreendentemente, porém, o próprio livro de Masson (1984), traz dados que indicam que Freud não desconsiderou totalmente a sedução. Uma carta inédita, de 12 de dezembro de 1897, três meses após o suposto abandono da teoria da sedução, na qual Freud reconhece, no caso Emma Eckstein, a validade da "etiologia do pai". Temos, assim, ao longo do livro de Masson (1984), um desenrolar de argumentos que vão mostrar, não apenas nessa carta, mas em outras fontes, que Freud não havia descartado o valor da sedução na histeria.

Masson (1984) afirma, então, que Ernest Kris teria ajudado Anna Freud a escolher as cartas do pai que seriam publicadas e partes dos textos de Freud que seriam omitidas; as partes omitidas seriam precisamente aquelas em que consta claramente que a teoria da sedução nunca teria sido abandonada completamente, dando provas clínicas de sua existência. Talvez aí esteja o "atentado à verdade". 
Como justificativa da omissão desse material, Masson presume que Anna Freud diria que se tratava de "não confundir" os herdeiros do pensamento de Freud, com dados que ainda estavam em elaboração.

É bem possível que esse argumento presumido por Masson (1984) subestime a capacidade dos leitores. Continuemos.

\section{Fantasia, trauma e sedução}

No entanto, autores como Laplanche (1992) e Piers (1996) consideram natural a busca de Freud por novos conhecimentos em que a fantasia seria uma extensão, ao invés da completa exclusão, da teoria da sedução. Piers (1996) considera até mesmo que a dinâmica psicopatológica permanece inalterada, nessa passagem da teoria da sedução para a teoria da fantasia, no que diz respeito à repressão e ao inconsciente dinâmico. $\mathrm{O}$ autor chama a atenção para os riscos que a retomada da teoria da sedução - como o discurso psiquiátrico propõe -traria para a clínica, uma vez que os pacientes poderiam construir uma identidade apenas em torno de sua vitimização, o que prejudicaria o tratamento.

Schimek (1987, citado por Piers, 1996), considera que a teoria da fantasia não foi uma negação dos relatos de abuso sexual, mas uma interpretação de Freud revisada a partir das associações dos seus pacientes.

Outros autores, como AdamsSilvan e Silvan (1994), ressaltam a importância da sexualidade infantil e da sedução infantil. Afirmam que Freud, nas suas "Conferências introdutórias em Psicanálise”, considera que o trauma - fantasiado ou não é causado por uma memória desprazerosa e provoca na pessoa estímulos incontroláveis, que não podem ser integrados, e dão origem à histeria. Os autores acreditam na existência do trauma de sedução como ocorrência de natureza real e não fantasiada, o que discutem apresentando um caso clínico, no qual a paciente foi seduzida pelo próprio irmão. No entanto, os autores afirmam que o trauma não é causado pela sedução ou por sua lembrança, mas pela perda de prazer ocasionada pelo fim da experiência sexual. É essa excitação que se procura repetir compulsivamente, ao mesmo tempo em que se tenta controlar esse estímulo perturbador.

McOmber (1996) não deixa de considerar a importância da teoria da sedução. Com ela, Freud não somente teria contestado a hereditariedade da patologia, mas, também, contradito tudo o que se acreditava sobre a sexualidade infantil e os procedimentos psiquiátricos. Esse primeiro momento, afirma McOmber (1996), representava uma tentativa de legitimação da psicanálise como ciência, uma vez que apresentava uma nova causa para a histeria, a sedução, e um novo método de tratamento. Apesar disso, o autor considera que essa importância é secundária, quando se compara com a técnica analítica, que evoluiu até a associação livre. E a técnica, para McOmber (1996), é o que efetivamente fundamentaria a validade do conhecimento psicanalítico. Ao contrário dos médicos da época, 
Freud, continua o autor, levou em consideração o discurso do paciente como ferramenta importante tanto para o tratamento quanto para a pesquisa da histeria.

De forma mais enfática, Morrant (1985) vai se manifestar contra as acusações feitas por Masson (1984), e vai devolver-lhe o retumbante adjetivo "covarde". Morrant sustenta que se Freud não tivesse deixado de lado as idéias equivocadas sobre a etiologia da histeria, jamais teria feito as descobertas que fez em torno da fantasia e da sexualidade, colocando em risco o progresso da psicanálise como ciência. Essa posição é compartilhada por Westerlund (1986) e pela maioria dos psicanalistas desde Jones (1979). Morrant (1985) recorre aos argumentos do próprio Masson (1984) para criticálo, principalmente quando este último acusa Freud de covarde, por ter abandonado a teoria da sedução em função de sua grande ambição de reconhecimento. Morrant (1985) enfatiza a imensurável humildade do pai da psicanálise em reconhecer insuficiências na sua teoria e procurar outras explicações. Entre os argumentos apresentados pelo autor está a inexperiência de Freud e o erro nos seus diagnósticos, fato confidenciado em carta a Fliess; tratava-se, a histeria, de "doença não reconhecida", de algum modo, portanto, pouco conhecida, ao menos pelo jovem Sigmund. Essa mesma inexperiência de Freud implicou que não fossem claros os verdadeiros diagnósticos de seus pacientes na época, incluindo aí o diagnóstico de histeria no célebre caso Emma Eckstein. Outro argu- mento chama atenção para o fato de que Freud não teria explicado por que a lembrança da experiência sexual teria de ser reprimida primeiramente e nem como se daria a produção do sintoma. Por outro lado, Freud também atribuíra o trauma de sedução não somente à histeria, mas também a outras psicoses funcionais, e Morrant (1985) pensa ser improvável que tais patologias dividam a mesma etiologia. Seria exagero pensar, continua o autor, que em todas essas patologias, ou em sua maioria, a causa teria sido a ocorrência de experiências sexuais assustadoras entre um adulto ou um irmão e uma criança.

Morrant também mostra o desconhecimento de Freud, nos primórdios da psicanálise, quando sustentava que crianças que não foram submetidas a um trauma de natureza sexual antes dos oito anos de idade nunca desenvolveriam histeria. Todavia, considera que as lembranças de abuso relatadas pelas pacientes de Freud teriam sido induzidas hipnoticamente por seu método inicial; método esse ainda marcado pela ingenuidade e inexperiência. Desse modo, ao longo de seu trabalho, o próprio Freud teria percebido o componente fantasioso da histeria, que daria um novo rumo a sua teoria?.

Quanto ao argumento de Masson, de que Freud teria abandonado a teoria da sedução por temer o isolamento profissional, Morrant (1985) afirma que isso não condiz com o que se conhece da personalidade de Freud. Basta lembrar as teorias posteriores, que também causaram polêmica e irritação, e nem por isso foram deixadas de lado. O autor men- 
ciona o conhecido fato, em 1910, quando diante de uma exposição de Freud, o prof. Wilhelm Weygandt teria afirmado: "isso não é um tópico para uma reunião cientifica. É assunto de polícia." (citado por Morrant, 1985, p. 397).

Esterson (1998), pelo mesmo caminho de Morrant (1985), afirma que os fundamentos sobre os quais Masson constrói seus argumentos são falsos e tendenciosos e faz uma revisão dos textos de Freud para demonstrá-lo. No fim dos anos 1970, diz Esterson, algumas feministas preocupadas com o abuso sexual de meninas concluíram que Freud, o Freud dos anos de 1897, estava errado em abandonar a teoria da sedução e acusaram-no de tê-lo feito em resposta à oposição combinada de seus colegas médicos (Herman, 1981; Pressa, 1977, 1980, citados por Esterson, 1998). Essa visão distorcida teria sido divulgada por Masson, no seu best-seller Atentado à Verdade... (1984), tentando argumentar academicamente, mas sem proceder a uma reinterpretação dos relatos de Freud em torno dos seus tratamentos e da passagem para a teoria da fantasia e sexualidade infantil. Para Esterson (1998), a visão revisionista de Masson do episódio parece ser nada além de senso comum.

O autor apresenta seus argumentos. Considera que Freud teria realmente induzido as pacientes a recordações traumáticas. De fragmentos de recordações comunicados pelos pacientes, Freud teria deduzido seduções. Os primeiros escritos, em torno da sedução e do trauma, teriam esse caráter de imprecisão, tendo em vista que não fora possível confirmar a veracidade do abuso sexual. As reivindicações de confirmações externas que Freud fez na ocasião são, para Esterson (1998), duvidosas.

O autor menciona o estudo de Smith (1991, citado por Esterson, 1998), que põe em dúvida, por exemplo, a confirmação de abuso sexual em vários casos. Num deles, o irmão mais velho teria negado experiências precoces com a irmã (a paciente). Outra "confirmação" dada por Freud teria vindo de duas pacientes que haviam se relacionado com o mesmo homem, mas isso não poderia significar uma confirmação de supostas experiências sexuais. Vejamos que, para Freud, a semelhança entre os sintomas de ambas as pacientes constituía o elemento confirmatório ${ }^{8}$. Esterson (1998) também vai referir-se à "confirmação", para Freud (em carta a Fliess de 3 de janeiro de 1897), de um caso de abuso sexual de um ex-paciente que teria vindo de uma fonte muito secundária, o que poderia dar lugar a distorções.

Também em A iniciação do tratamento (1913, citado por Esterson, 1998), Esterson assinala evidências de que teria sido o próprio Freud quem dissera aos seus pacientes que, na sua infância, haviam 
sofrido de abuso. A impossibilidade de recordar tais eventos se explicaria pelo componente traumático da experiência.

Quanto à culpabilidade do pai, Esterson (1998) chama a atenção para a carta de 21 de setembro de 1897, especialmente para o trecho citado por Masson, onde se lê : "Então, a surpresa que em todos os casos o pai, não excluindo o meu próprio, tinha de ser acusado de perverso" (Masson, 1984, citado por Esterson, 1998, p.11). Recorrendo, pois, ao texto em alemão, afirma que Freud não escreveu 'tinha sido acusado', mas 'tinha de ser acusado'. O que o autor entende como uma referência de Freud oriunda de suas recentes noções especulativas, isto é, de quando concluíra que os pais eram os abusadores. $\mathrm{O}$ fato de ter incluído o próprio pai, indica, para Esterson (1998), que isso se refere à natureza conjetural de Freud, tendo em vista que, na carta de 8 de fevereiro de 1897, ele havia se referido aos sintomas histéricos de vários dos seus irmãos. $\mathrm{O}$ pesquisador também se refere à carta de 4 de maio, do mesmo ano, em que Freud confidencia a Fliess um dos seus sonhos, que remeteria a "seu desejo de tomar um pai como o originador da neurose" (citado por Esterson, 1998, p. 10).

Quanto aos dois casos de Estudos sobre a histeria (1896, citado por Esterson, 1998), em que o próprio Freud teria revelado, anos mais tarde, que era o pai o abusador (caso Katharina e caso Rosalia - mencionado no caso Elisabeth von R), o autor chama a atenção para o fato de que não se poderia pensar na teoria da sedução nesses casos, não somente porque Katharina não era paciente de Freud, mas porque ambas tinham idade além da infância quando a suposta sedução ocorrera. Além disso, Esterson (1998) afirma que feministas como Rush e Herman (1980,1981 respectivamente, citadas por Esterson, 1998) parecem desconhecer que essas substituições do pai por um tio, feitas por Freud, visavam preservar a identidade das jovens; mesmo assim, consideram que tal fato evidencia que Freud estava escondendo abusos patriarcais. Vimos que Bayer e Connors (1988) pensam de forma semelhante a essas autoras.

Esterson (1998) também vai se referir à inconsistência de $A$ etiologia da histeria, que, para Masson, teria sido o melhor artigo de Freud. No entanto, diz Esterson, trata-se de um texto excessivamente persuasivo. Além disso, comentaristas como Israëls e Schatzman (1993), Salyard (1994), Scharnberg (1993), Smith (1991), Thornton (1983) e Wilcocks (1994), citados por Esterson, (1998), consideram que o texto de Freud apresenta erros, sendo, por vezes, ambíguo e confuso. Thornton, por exemplo, sugere que há muitas discrepâncias no texto e os argumentos circulares indicariam uma dificuldade crítica de Freud, nessa época. Wilcocks, por sua vez, sustenta que a confabulação e a falta de evidência caracterizam esse artigo. 
Quanto a Estudos sobre histeria, Esterson (1998) também vai se referir à crítica de Kiell (1988, citado por Esterson, 1998), que considera que a técnica descrita por Freud (método catártico) evocaria material de autenticidade duvidosa, a qual, no entanto, teria impressionado a audiência da conferência em que Freud o apresentara.

Continuando com os argumentos relativos à falta de compreensão de Masson, Esterson (1998) apresenta mais um dado: Masson (1990/1993, citado por Esterson, 1984), referindo-se aos Estudos sobre a histeria, afirma: "neste momento Freud disse que a resposta tinha que ser sedução, e por 'sedução' ele quis dizer algo muito sério, o que nós chamaríamos hoje atentado ao pudor. Isso correspondeu realmente a incesto" (p.13). Para o autor, essa passagem é mais um exemplo de uma interpretação incorreta de Masson sobre a teoria de sedução, e argumenta:

"Freud descreveu os incidentes prematuros supostos como 'experiências sexuais que afetam o próprio corpo do sujeito' e, entretanto, ele escreveu que alguns destes incidentes eram 'agressões brutais'; em outro lugar ele declarou que ' $\mathrm{Na}$ base $\mathrm{da}$ etiologia da histeria nós achamos um evento de sexualidade passiva, uma experiência a qual se submeteu com um grau pequeno de aborrecimento ou medo' (ibid: 203, 152, 155). Sua teoria de 'efeito retardado' meramente requeria algum grau de excitação sexual; incesto era só um exemplo extremo do tipo de experiência vasta cercada pela teoria da sedução". (Esterson, 1998, p. 8).
Outro argumento apresentado pelo autor, diz respeito ao mito criado em torno da rejeição de Freud por seus colegas médicos nos primórdios da psicanálise. O próprio Masson não escaparia a isso, e sobre esse mito basearia sua revisão da teoria da sedução. Para Esterson (1998), contudo, a rejeição de Freud por parte dos colegas é uma história propagada pelo próprio Freud e por seu biógrafo Ernest Jones. O autor lembra então que, em 1897, uma assembléia de professores médicos apoiou a nomeação de Freud para ocupar a posição de Professor Associado na Universidade de Viena, conforme mostraram os trabalhos de Ellenberger, 1970 e Sulloway, 1979 (citados por Esterson, 1998). Também, continua o autor, Masson interpreta mal as palavras excêntricas e um tanto paranóicas de Freud, quando diz a Fliess: uma "ordem foi dada para me abandonarem" (citado por Esterson, 1998, p. 13) e esquece que foi o próprio Freud que decidiu, seguindo o conselho de Fliess, isolar-se dos colegas antes de apresentar seu artigo da 'Etiologia'.

Por esse mesmo caminho, Esterson (1998) vai mostrar outros momentos em que Masson faz um relato tendencioso. Em torno da teoria da sedução, afirma o autor, Masson compõe uma mistura de erros, falta de compreensão, e especulações mascaradas como fatos. Por exemplo, Masson (citado por Esterson, 1998) considera que, em carta de 1893, dirigida a Fliess, Freud confirma um caso de abuso sexual infantil; contudo, Esterson (1998) chama a atenção para o fato de que se trata somente 
de uma entre três conjeturas sobre casos de 'neurastenia juvenil sem masturbação', sobre as quais Freud está pedindo a opinião de Fliess: o que é mais importante para mim, diz Freud, "é a atenção que você presta no procedimento que tenho empregado" (citado por Esterson, 1998, p.15). O que desse momento é importante, interpreta Esterson (1998), é a descoberta da técnica analítica como meio de conhecimento das lembranças inconscientes dos pacientes e a possibilidade de reconstruir o passado infantil.

E voltando à questão do pai, Esterson (1998) considera que, para Freud, em meio a essa seqüência de descobertas, não era mais importante descobrir a identidade dos supostos culpados. Nos artigos publicados em 1904 (O método psicanalitico de Freud) e 1914 (Contribuições à história do movimento psicanalitico) (citados por Esterson, 1998), continua o autor, a principal preocupação de Freud girava em torno da descoberta de que a maioria dos traumas sexuais infantis estava associada a fantasias inconscientes criadas durante os anos de puberdade para 'encobrir' lembranças de masturbação infantil. Ora, digamos nós, o método psicanalítico propriamente dito pode parecer mas não é uma investigação factual, de eventos na realidade material. E é isso que Masson critica e é isso que Esterson está dizendo ser tendencioso.

Esse último se refere também a Um estudo autobiográfico (1925, citado por Esterson, 1998), onde Freud reconhece que as cenas de sedução eram fantasias, sejam inventadas, sejam forçadas por ele mesmo, e isso o faz rever o método técnico. Novamente vai considerar a relação entre sintomas neuróticos, fantasias e desejos e, como esperado, vai atribuir grande importância à realidade psíquica sobre a realidade material.

Com esses argumentos, Esterson (1998) afirma que Masson construiu uma versão errônea dos episódios relacionados à teoria de sedução, por sua "incapacidade para distinguir entre fatos, conclusões, e especulações" (Rycroft, 1991, citado por Esterson, 1995, p. 17).

Finalmente, Esterson chama a atenção para as palavras de Cioffi (1974, citado por Esterson, 1998), sobre a impossibilidade do próprio Freud de reconhecer o raciocínio que o levou a supor a autenticidade das seduções. É que esse será precisamente o mesmo caminho argumentativo que guiará Freud nas suas descobertas sobre a fantasia infantil e o conteúdo do inconsciente de modo geral.

De forma semelhante, enfim, outro autor, Piers (1996), também virá, contra Masson, em defesa de Freud. Para ele seria exagero pensar que Freud teria desconsiderado a importância do abuso sexual. O que Freud fez foi perceber que experiências de qualquer tipo apenas ganham significância dentro da psicologia do paciente.

Contudo, Morrant (1985) considera que entre a experiência real e a fantasia pode haver uma relação dialética. Idéia essa que encontraremos em Laplanche e a vimos em Gammelgaard (1992). 


\section{Da sedução à fantasia: motivos latentes}

Teria Freud modificado a teoria da sedução apenas por temer isolamento profissional e para se promover? Masson e seus seguidores afirmam que sim. Mas, haveria alguma outra razão? Os autores, ao acusarem Freud, estariam sendo movidos apenas pelo sofrimento das pequenas vítimas? E os que o defendem e justificam as críticas à teoria do trauma de sedução, estariam também reagindo frente a uma evidência chocante que precisaria ser escondida e esquecida?

É o que propõe Westerlund (1986). A autora se baseia, como outros autores, no livro de Masson (1984) e recorda-nos que Freud elaborava sua teoria da sedução enquanto passava por um processo de auto-análise. Descobrindo-se histérico, passa a suspeitar da sedução do seu pai. Além disso, Freud descobre sentimentos incestuosos por sua filha e com essa evidência, a de que os pais podem ter desejos sexuais por seus filhos, ele teria repudiado sua própria teoria, já que ela devolveria um reflexo horrível de sua própria família.

O abandono da teoria da sedução teria sido resistência? Westerlund (1986) sustenta que Freud preferiu se declarar equivocado, do que suportar essa realidade.

Outros autores vão acusar Freud de maneira mais enfática. Smith (2000), por exemplo, criticará Freud por ter se afastado de Breuer e inclusive por ter formulado a teoria da sedução?. A autora também acusa o pai da psicanálise de ser tolo e ambicioso. Afirma que Freud fez generalizações a partir de poucos casos e se a sua teoria tem importância para a Psicologia, teria sido pelo mérito de outros autores. Sobre a teoria da sedução, Smith considera que Freud deveria tê-la considerado adequada apenas a alguns casos. Reconhece o mérito de Freud ao questionar a origem da histeria e a partir disso criar um novo método de intervenção, o método catártico. No entanto, considera que a obsessão sexual de Freud o teria afastado de Breuer. Isso precisamente porque Freud desejava clamar toda a fama para si. Eis que surge a teoria da sedução, segundo a autora, para promover Freud, cuja "obsessão agitada e infantil alimentava sua necessidade de fama e reconhecimento" (Smith, 2000, p. 508).

Temos, assim, autores que não somente irão criticar o abandono da teoria de sedução, mas a própria teoria da sedução. Daí a necessidade que têm de voltar a Charcot, Janet e Breuer, numa tentativa de óbvia dessexualização da histeria e da psicanálise. Ao final, a face de Édipo é sempre "medusante" 10 . 
Freud buscava a fama? Talvez sim, mas talvez não de uma forma tão mesquinha como quer a autora. Porém, acreditamos que, mais importante do que os motivos internos que guiaram Freud em sua jornada, pois nunca saberemos ao certo, é o destino de seu legado.

Chegamos assim ao trabalho de Laplanche, sem diminuir a importância de tantos outros autores, e podemos supor que a teoria da sedução, de Freud, permite-lhe elaborar a sua teoria da sedução generalizada.

\section{Sedução generalizada e trauma: a herança de Freud}

Laplanche (1974) presidiu, em 1973, uma mesa redonda sobre a histeria, que deu subsídios para a elaboração de um relatório, de sua autoria, intitulado "Panel on 'hysteria today". Nesse evento discutiram-se as concepções de histeria na atualidade, tendo em vista que esta não se caracteriza mais como algo puro, como Freud a definia, podendo estar ainda associada a outras patologias. Ali, de algum modo, Laplanche (1974) enfatiza a disposição à histeria da maneira vista por Freud, ressaltando os elementos de sedução sexual e a passividade, propostos pelo pai da psicanálise, porém considerando, nesse sentido, a estimulação sensual trazida pelos cuidados maternos.

O autor sustenta, pois, que a sedução oral já é uma sedução, e que a excessiva estimulação oral já é uma excessiva estimulação sexual. Nisso já podemos vislumbrar algo da sua teoria da sedução generalizada, que só aparecerá no fim dos anos 80 .

Em Novos fundamentos para a psicanálise (1992), Laplanche expõe o desenvolvimento e a aplicabilidade da teoria da sedução. No entanto, vê na sedução focal proposta por Freud algo um tanto limitado, uma sedução restrita. Freud considerava a etiologia da histeria algo exclusivamente resultante de fatores exógenos, ou seja, somente a partir da reativação de uma lembrança de sedução é que se originava o trauma. Com o abandono da teoria do trauma de sedução, Freud, então, passa a considerar outros aspectos, ou seja, a influência dos fatores endógenos, concernentes ao indivíduo, aspectos biológicos, as pulsões, no que se refere à sexualidade infantil, no desenvolvimento da histeria. Esse novo enfoque dado à fantasia também teve seu valor, uma vez que a idéia de pai perverso foi substituída pelos cuidados corporais direcionados à criança, que originam o prazer sexual, dando assim uma base concreta à fantasia. 
Entretanto, Laplanche (1992), ao contrário de alguns autores, como vimos, afirma que a teoria da sedução não foi completamente abandonada, sendo a fantasia o seu complemento ${ }^{11}$. Laplanche (1992), contudo, considera que Freud enfatizou, na fantasia, a questão genital, esquecendo-se da erogeneidade anal e oral, isto é, de uma sexualidade mais genérica e sutil, o que indica que essa teoria poderia ter sido mais bem desenvolvida. E é isso que esse autor se propõe a fazer em sua teoria da sedução generalizada.

O autor aborda principalmente, em sua proposta, a questão da passividade da criança face à atividade do adulto na relação. Desse modo, vemos que Laplanche (1992) retoma o pensamento de Ferenczi em termos da situação originária, na qual a criança é seduzida e o adulto é um sedutor; de fato, este último, apesar de atender às demandas da criança, em termos de cuidados e carinhos, ignora o sentido sexual que por ele mesmo transmite, dessa maneira, à criança. O caráter traumático residiria no fato de que o psiquismo infantil não está estruturado a ponto de assimilar, de forma satisfatória, as significações sexuais inconscientes do adulto, o que o autor denomina significantes enigmáticos. Dentre eles, temos aquilo que se relaciona ao que Freud supôs como mais traumático na vida infantil: a cena originária, a diferença de gêneros, o nascimento de um outro filho, de forma a demonstrar que a sedução originária não estaria presa, exclusivamente, ao abuso sexual. Dessa maneira, Laplanche (1992) caracteriza a sedução origi- nária como um complemento à sedução precoce (cuidados "maternos") ou à sedução infantil ("ataques" paternos), uma vez que esse modelo considera a erogeneidade da criança em todos os aspectos, bem como é demonstrada, através dela, a importância da relação atividade-passividade.

A nova teoria do trauma de que falamos no início, que recupera a tradição de Charcot e Janet, e os primórdios do trabalho de Freud, é também, como vimos, um dos legados do vasto edifício freudiano. Trata-se, porém, de um discurso; esse da nova teoria do trauma, que nasce fora do âmbito psicanalítico (Piers, 1996) ${ }^{12}$ e utiliza outros parâmetros de conceituação como, por exemplo, os do D.S.M. IV e o C.I.D. 10. Ora, isso nos coloca o problema da dessexualização da histeria. Não se trata mais de psicanálise.

\section{Brevíssimas considerações finais}

Da polêmica levantada por Masson (1984), temos pelo menos três pontos de vista. Aquele mais radical que critica Freud por ter abandonado Breuer e formulado a teoria da sedução; o ponto de vista que acusa Freud por ter privilegiado a fantasia em detrimento da sedução real, traindo uma verdade; aquele que considera a teoria da fantasia um desdobramento da teoria da sedução, marcando uma evolução natural no conhecimento de Freud, isto é, da própria psicanálise. $\mathrm{O}$ interessante é que em muitos desses diversos discursos 
revelam-se sujeitos implicados numa tomada de posição "moral”. Assim, encontramos argumentos exaltados, seja para chamar Freud de covarde, seja para inocentá-lo.

Isso por um lado. Por outro, essa diversidade de discursos permite uma volta a Freud, mostrando a sua atualidade e produzindo inovações. McOmber (1996), por exemplo, secundariza a importância da teoria da sedução face à importância da criação do método de associação livre, enquanto Gammelgaard (1992) refere-se à possibilidade de um trabalho fantasmático de ocultação de uma sexualidade auto-erótica atrás da fantasia de sedução e passividade. ${ }^{13}$

Laplanche (1974, 1992), vimos, fala de uma sedução generalizada. Isso significa que, para a discussão da histeria, seja porque ainda se defende a recuperação da teoria da sedução, seja porque se defende a teoria da fantasia, haveria também uma multiplicidade de enfoques. A histeria, afirma Mello Neto (2007), é vista atualmente não mais como algo bem definido, como o era nos tempos de Freud. Isso traz dúvidas não apenas sobre o que é a histeria, mas também sobre a sua etiologia, suas manifestações e, conseqüentemente, as formas de tratamento que requer.

Todavia, se nos voltamos para a defesa da teoria da sedução focal, do primeiro Freud, e para o clamor pelo seu resgate, o que fazer com a própria psicanálise? Isso nos levaria também a ter que questionar nossas próprias convicções, uma vez que se trataria de uma espécie de revelação de que não somos filhos legítimos do pai. A psicanálise, pois, decorre não só da teoria da sedução, mas de todo o arcabouço freudiano e pós-freudiano.

Outro aspecto a ser ressaltado é que vários argumentos dos "acusadores" fazem-nos pensar que, na sua compreensão da psicanálise, eles teriam parado na carta 69. Para Mello Neto (2007), por exemplo, as acusações de Masson (1984) contra Freud levam a supor que o primeiro a falsificar a psicanálise teria sido o seu próprio criador, ao mudar a sua teoria do trauma de sedução. E continua: "A proposta de Masson é retomar o trauma de sedução e o abuso como explicativos da neurose, portanto repor a psicanálise em seus antigos trilhos. O que ele não nos diz é se propõe também a retomada do método catártico. Essa seria, a meu ver, uma técnica bem mais em acordo com tais idéias. Concordo com Allen Esterson que teria faltado à Masson uma correta avaliação do método clínico de Freud no episódio da teoria da sedução" (Mello Neto, 2007, p. 190).

Laplanche (1992) também vai criticar Masson e seus seguidores, rapidamente e sem dar-lhes muita importância. Considera que esses autores acabam por se prender, em demasia, à discussão sobre a realidade ou não do trauma, esquecendo-se da necessidade de retornar à teoria da sedução para revisá-la. A nosso ver há algo mais grave que isso: Masson (1984) detém-se, sobretudo, em aspectos supostamente morais, e não tem nenhuma proposta de exame teórico e clínico da idéia de sedução focal.

A carta 69, de Freud a Fliess, de 1897, segundo Laplanche (1992), ain- 
da é considerada, tanto por Masson (1984) quanto por outros autores, como a indicação de que Freud renunciou à sua teoria. Percebe-se, porém, que essa carta, por si só, não forneceria fundamentos suficientes para constatar esse abandono. O próprio Freud não teria se aprofundado sobre os motivos mencionados que o levaram a duvidar de sua neurótica. Dessa maneira, para Laplanche (1992), o pensamento de Masson perde-se em um tecido de insuficiência, dúvidas e elementos totalmente subjetivos.

Contudo, as "acusações" contra Freud não deixam de ser interessantes, seja no sentido de retomar a obra de Freud através dessa discussão, seja no sentido de se construir a própria história da psicanálise. Assim, continuamos a nos surpreender com o inconsciente.

Encerramos o artigo, trazendo as palavras do próprio "pai" da psicanálise, ou, quem sabe, o "pai" de uma espécie de horda intelectual, na qual os filhos ora o invejam, ora o admiram: “... quando, à custa de penosos esforços, adquirimos uma convicção, também temos, até certo ponto, o direito de querer mantê-la contra todos e apesar de tudo. Aliás, faço questão de acrescentar que no decorrer dos meus estudos, em mais de um ponto importante mudei, modifiquei ou substitui por outras algumas de minhas opiniões e que nunca deixei de fazer dessas variações uma declaração pública. Qual o resultado de minha franqueza? Uns não tiveram o menor conhecimento das correções que introduzi e ainda hoje me criticam por proposições a que já não atribuo o mesmo sentido de outrora. Outros, que censuram precisamente estas variações, declaram que não posso ser levado a sério. Dir-se-ia que aquele que modifica de vez em quando suas idéias não merece confiança alguma, pois deixa supor que suas últimas proposições são tão errôneas como as precedentes. E, por outro lado, aquele que mantém suas primeiras idéias e delas não se deixa desviar facilmente, passa por teimoso e transviado. Diante destes dois juízos opostos da crítica, só há um partido a tomar; continuar a ser o que somos, e seguir apenas nosso próprio critério. É efetivamente ao que estou decidido, e nada me impedirá de modificar e corrigir minhas teorias com o progresso da minha experiência” (Freud, 1916, p. 225).

Eis a enorme coragem de Freud.

\section{Abstract}

HYSTERIA, TRAUMA AND SEDUCTION: "WHAT DID THEY MAKE POOR CHILD” (A COWARD FREUD?)

The accusations of Masson against Freud, for having abandoned the theory of the seduction, they inaugurated a controversy around the validity of that theory, in the explanation of the hysteria and around the own psychoanalysis. Followers propose the turn of that theory, denouncing the infantile abuse, and they accuse coward's Freud and ambitious. Already the opponents see in that supposed abandonment, no the disregard with the childhood, but the possibility of the development of the psychoanalysis. We analyzed those speeches and we concluded that Frend, starting from the theory of the seduction, left his inberitance: the theorization, for the psychoanalysis, around the fantasy and of the infantile sexuality and, among other contributions, dispersed elements with which Laplanche can elaborate the general theory seduction.

Index terms: abuse sexual; trauma; childhood; bysteria; infantile sexuality; psychoanalysis 


\section{RESUMEN}

HISTÉRIA Y TRAUMA DE SEDUCCIÓN: "QUE TE HICIERON POBRECITO?" (UN FREUD COVARDE?)

Las acusaciones de Masson contra Freud, por haber abandonado la teoria de la seducción, abrieron una polémica sobre la validad de esa teoria en la explicación de la histéria y sobre el própio psiconálisis. Los seguidores proponen que se retome esa teoria, pues denúncian el abuso infantil y acusan Freud de covarde y ambicioso. Ya los opositores no ven, en ese supuesto abandono, el descaso con la infancia, mas la posibilidad del desarrollo del psicoanálisis. Analizamos esos discursos y concluimos que Freud, a partir de la teoria de seducción, dejó su herencia: la teorização, para el psicoanálisis, sobre la fantasia y la sexualidad infantil y, entre otras contribuiciones, elementos dispersos con los quales Laplanche pudo construir su teoria de la seducción generalizada.

Palabras clave: abuso sexual; trauma; infância; histeria; sexualidad infantil; psicoanálisis

\section{REFERÊNCIAS BIBLIOGRÁFICAS}

Adam-Silvan, A.; Silvan, M. (1994). Paradise lost: A case of hysteria illustrating a specific dynamic of seduction trauma. International Journal of Psycho Analysis. Inglaterra: Inst of Psychoanalysis, 75 (3), 499-510.

Bayer, T.; Connors, R. (1988). The emergence of child sexual abuse from the shadow of sexism. Response to the Victimization of Women and Children. EUA: Response, Inc., 11 (4), 12-15.

Esterson, A. (1998). Jeffrey Masson and Freud's seduction theory: a new fable based on old myths. History of the Human Sciences, 11 (1), p. 1-21.

Freud, S. (1989). XVI Conferência. Psicanálise e Psiquiatria. In S. Freud, Obras Completas, Vol. XVI (pp. 223-234). Buenos Aires: Amorrortu. (Trabalho original publicado em 1916).

Gammelgaard, J. (1992). They suffer mainly from reminiscences. Scandinavian-Psychoanalytic-Review. Dinamarca: Munksgaard International Publishers Ltd, 15 (2), 104-121.
Huopainen, H. (2002). Freud's view of hysteria in light of modern trauma research. Scandinavian-Psychoanalytic-Review. Dinamarca: Munksgaard International Publishers, 25 (2), 92-107.

Jones, E. (1979). Vida y obra de Sigmund Freud (M. Carlisky, trad.). Buenos Aires: Ediciones Horme.

Laplanche, J. (1974). Panel on 'hysteria today'. International Journal of Psychoanalysis. Grã-Bretanha: Instituto de Psicanálise, 55(3), 459-469.

(1992) Novos fundamentos para a psicanálise (C. Berliner, trad.). São Paulo: Martins Fontes.

Martinez, V. C. V. (1996). A figura do herói na mitologia: um guerreiro além do bem e do mal. Psicologia em Estudo, 1(1), 27-58.

Masson, J. M. (1984). Atentado à verdade: A supressão da teoria da sedução por Freud (A. M. Sarda, trad.). Rio de Janeiro: Livraria José Olímpio Editora.

McOmber, J. B. (1996). Silencing the patient: Freud, sexual abuse, and 'The Etiology of Hysteria'. Quarterly Journal of Speech. EUA: Speech Communication Assn, 82 (4), 343-363.

Mello Neto, G. A. R. (2005). Sobre a histeria, ainda: o discurso sobre a histeria, em psicanálise nos últimos cinqüenta anos. Relatório final de pesquisa financiado e provado pelo CNPq e a Universidade Estadual de Maringá, PR.

- (2007). Psicanálise e histeria depois de Freud. Campinas, SP: Editora da Unicamp. No prelo.

Morrant, J. C. (1985). In defense of Sigmund Freud against Masson's charge of cowardice. Canadian Journal of Psychiatry. Canadá: Canadian Psychiatric Assn, 30 (6), 395-399.

Piers, C. (1996). A return to the source: Rereading Freud in the midst of contemporary trauma theory. Psychotherapy: Theory, Research, Practice, Training. EUA: Div of Psychotherapy APA, 33 (4), 539-548. 
Smith, C. (2000). Sigmund Freud: The ambition theory. Psycbologist. Inglaterra: British Psychological Society, 13 (10), 508-509.

Wasserman, S., \& Rosenfeld, A. (1992). An overview of the history of child sexual abuse and Sigmund Freud's contributions. Clinical issues. EUA: Human Sciences Press, Inc., 2, 49-72.

Westerlund, E. (1986). Freud on sexual trauma: An historical review of seduction and betrayal. Psychology of Women Quarterly. Reino Unido: Blackwell Publishers, 10 (4), 297-310.

\section{NOTAS}

1 Pesquisa financiada pelo CNPq (relatório final aprovado em 12/2005).

2 Do ponto vista de Huopainen (2002), o trauma consiste na sobrecarga da capacidade de processamento emocional do indivíduo, causando uma dissociação psicofisiológica no encadeamento da memória, fragmentando-a e isolando-a, dando origem à histeria. Assim ocorreria uma desintegração da personalidade, o que faria com que o trauma fosse revivido inúmeras vezes, à revelia da pessoa, dando origem aos sintomas. A dissociação se manifestaria, então, à medida que o indivíduo oscilasse entre uma personalidade normal e uma personalidade emocional. $\mathrm{O}$ autor recorre também às explicações dos próprios Freud e Breuer, dos "Estudos sobre a Histeria", sobre o estado traumático ocasionado principalmente porque esse estímulo que não pode ser processado, causando desesperança e terror mudo.

${ }^{3}$ Essa é precisamente a denúncia das feministas; denúncia que já encontramos desde o Antigo Testamento. A história de Lot é elucidativa, afirmam Wasserman e Rosenfeld (1992), pois, embriagado por suas filhas, unese incestuosamente a elas. A história, dentro de uma perspectiva patriarcal, protege o homem da culpa, de tal maneira que Lot passa a ser a vítima inocente da sedução de suas filhas.

${ }^{4}$ Masson (1984) é bastante citado na maior parte dos artigos.

5 Os primeiros trabalhos aparecem em 1860 e estendem-se até a época da passagem de Freud em Paris. (Masson, 1984).

${ }^{6}$ Estamos numa época em que o discurso explicativo em torno dos males está fortemente impregnado pelo Tratado das degenerescências (Morel, 1857), cujas idéias em torno da degenerescência da espécie humana vêm da doutrina do pecado original, sistematizada por Santo Agostinho no século V.

7 O leitor poderá espantar-se pelo fato de que Morrant (1985), a princípio, propõe-se a defender Freud, mas até aqui não faz muito mais que criticá-lo. No entanto, veja-se que a crítica dirige-se justamente àquilo que Masson defende com unhas e dentes: o trauma de sedução. Além disso, vejamos que Morrant está enfatizando a própria autocrítica de Freud.

8 Notemos que é uma confirmação "interna" e não pode ser fatual; portanto, não é uma confirmação. Mas vejamos que já está aí outro tipo de "confirmação", aquela ligada à realidade psíquica, aquela do método psicanalítico e que diz respeito à fantasia e à interpretação.

${ }^{9}$ Discurso semelhante ao da nova teoria do trauma.

10 Embora não exista essa palavra na língua portuguesa (do verbo méduser, em francês, que significa assombrar), Martinez (1996) utiliza-a, como licença metafórica, em franca alusão à Medusa.

${ }^{11}$ Lembremos a idéia de dialética para Morrant (1985).

140 Estilos da Clínica, 2007, Vol. XII, n²2, 122-141 
12 Piers (1996) aponta uma série de problemas nessa nova teoria, o que precisamente torna-a alheia à psicanálise. Apesar de essa teoria manter a idéia de experiências segregadas da memória do paciente, ela leva em consideração não apenas os aspectos emocionais do trauma, mas a falta de maior processamento cortical durante e depois do trauma. Ao contrário de Freud, considera que a lembrança fica em estado passivo, isolada do resto da mente, só entrando em ação em situações que aludem ao trauma anterior. Essa falta de dinamismo, pela negação do esquecimento defensivo do trauma, como a repressão em relação aos sintomas, e, portanto, da ação do ego contra as idéias indesejadas, diz Piers, pode estabelecer uma relação causal simplista entre o trauma e a psicopatologia, o que levaria ao erro, principalmente na clínica. $\mathrm{O}$ terapeuta pode ser levado a prenderse apenas aos relatos de seus pacientes sobre o trauma, de forma que acabe sugestionando-os ou focalizando falsas lembranças produzidas por eles, o que terminaria por obscurecer aspectos inerentes à dinâmica psíquica do paciente.

13 Evidentemente, isso não é inteiramente novo, pois, para Freud, todo fantasma tem finalidade auto-erótica.

vcvmartinez@hotmail.com garmneto@hotmail.com mindstudent01@yahoo.com.br

Recebido em novembro/2006.

Aceito em fevereiro/ 2007. 